\title{
Vasopressin and oxytocin gene expression in the supraoptic and paraventricular nucleus of the spontaneously hypertensive rat (SHR) during development of hypertension*
}

\author{
Hubert H.M. van Tol, Maarten van den Buuse, Wybren de Jong and J. Peter H. Burbach \\ Rudolf Magnus Institute, Medical Faculty, University of Utrecht, Utrecht (The Netherlands)
}

(Accepted 2 August 1988)

Key words: Vasopressin; Oxytocin; Spontaneously hypertensive rat; Hypertension; Gene expression; Supraoptic nucleus; Paraventricular nucleus

\begin{abstract}
To study the regulation of hypothalamic vasopressin (VP) and oxytocin (OT) gene expression in relation to the development of hypertension, levels of VP mRNA and OT mRNA were determined in spontaneously hypertensive rats (SHR). Differences in VP and OT mRNA content of the supraoptic nucleus (SON) and paraventricular nucleus (PVN) of 4- and 10-week-old SHR and Wistar-Kyoto controls (WKY) were quantitated by dot-blot and Northern blot analysis. VP and OT pituitary content and VP plasma levels were measured by radioimmunoassays. VP mRNA levels were approximately 2-fold and 3-fold higher in the SON and PVN of 4-week-old SHR, respectively, as compared to controls. The OT mRNA levels were approximately $35 \%$ lower in both nuclei of the SHR. There was no difference in VP and OT pituitary content between 4-week-old SHR and WKY, but VP plasma levels were higher in SHR. In the 10-week-old SHR VP mRNA levels were still approximately 30-40\% higher and the OT mRNA levels were approximately $40 \%$ lower in both nuclei when compared to age-matched WKY. Pituitary VP and OT contents were respectively 1.5 -fold higher and $20 \%$ lower in the 10-week-old SHR than in 10-week-old WKY. VP plasma levels were still elevated in the SHR. The data indicate that in the hypothalamo-neurohypophyseal system of the SHR the VP system is in a higher state of activity, while the OT system is lower in activity.
\end{abstract}

\section{INTRODUCTION}

The spontaneously hypertensive rat (SHR) is characterized by a rise in blood pressure with age. During the first month after birth blood pressure is only slightly higher in the SHR when compared to Wistar-Kyoto controls (WKY), but at an age of approximately 2 months the SHR is clearly hypertensive $^{30}$. Several reports have suggested that vasopres$\sin$ (VP) is involved in the development of high blood pressure of the $\mathrm{SHR}^{20,42}$. This suggestion is based on the vasoconstricting properties of $\mathrm{VP}^{20.41}$ and the observed alterations in the VP system of the SHR. In the SHR higher plasma VP levels have been reported ${ }^{7}$,
$16,20,22,25,36,41$ as well as pituitary VP contents as compared to $\mathrm{WKY}^{7,8,16,23,36}$. Furthermore, there are indications that the SHR is hyper-responsive in its VP release following several stimuli ${ }^{6,8,25-27.35}$. Besides changes in the VP system, alterations in the oxytocin (OT) system have also been reported for the SHR. The SHR has lower plasma OT levels and pituitary contents $^{23,26,36,41}$. The magnitude of the changes may not be sufficient to explain the degree of hypertension $^{16.20}$ and may be related to strain differences. However, the SHR and the genetically related WKY rat may provide an animal model for studies on VP and OT gene expression, biosynthesis and release.

In this paper we have investigated whether

\footnotetext{
* Part of this study was presented as abstract at the 11th Scientific Meeting of the International Society of Hypertension, Heidelberg, J. Hypertens., 4 (1986) S599.

Correspondence: J.P.H. Burbach, Rudolf Magnus Institute, Medical Faculty, University of Utrecht, Vondellaan 6, 3521 GD Utrecht, The Netherlands.
} 
changes in the expression of the VP and OT genes of the SHR underlie the altered pituitary and plasma levels of the neurohypophyseal hormones. The major site of synthesis of VP and OT in the pituitary gland is in the magnocellular neurons of the supraoptic nucleus (SON) and the paraventricular nucleus (PVN) of the hypothalamus. The PVN also innervates extra-hypothalamic brain areas ${ }^{12,33,46}$. Therefore, VP and OT mRNA levels were measured in the SON and PVN of SHR and WKY during the period in which hypertension develops. The data indicate that the SHR is more active in expressing the VP gene and less active in OT gene expression than the WKY. The greatest difference in VP and OT gene expression between the strains occurs before hypertension is fully developed. It demonstrates that the alterations in the VP and OT systems are constitutive and not caused by increased bloot pressure per se.

\section{MATERIAL AND METHODS}

\section{Animals and tissue preparation}

Male SHR and WKY of 4 and 10 weeks of age (own breeding of the strains provided by TNO-CPB, Zeist, The Netherlands) were used. The brain and pituitary gland were immediately removed from the skull after decapitation, frozen on dry ice and stored at $-70^{\circ} \mathrm{C}$. Plasma was obtained from trunk blood and stored at $-20{ }^{\circ} \mathrm{C}$. The SON and PVN were isolated from the brains by the punch technique of Palkovits $^{32}$. A constant number of punches containing the whole nucleus (10 punches from 5 slices of $300 \mu \mathrm{m}$ per nucleus) was used. Equal amounts of cortex tissue were isolated. Furthermore, in situ hybridization showed that VP mRNA and OT mRNA is present only in the soma of the VP- and OT'producing neurons $^{4.19}$. Therefore the data were expressed per whole nucleus instead of per protein content.

Blood pressure was measured in age-matched groups of frecly moving SHR and WKY via an indwelling carotid cannula which was implanted one day before under ether anesthesia.

\section{RNA extraction}

The isolated SON, PVN and cortex tissue were homogenized in $200 \mu \mathrm{l} 4 \mathrm{M}$ guanidine thiocyanate, 0.1 $\mathrm{M} \beta$-mercaptoethanol, $25 \mathrm{mM}$ sodium citrate, $\mathrm{pH} 7.0$ by suction through a 21 -gauge needle. The homoge- nate was extracted with $200 \mu \mathrm{l}$ phenol-chloroformisoamylalcohol $(25: 24: 1, \mathrm{v} / \mathrm{v} / \mathrm{v}), \mathrm{pH} 8.0$. The aqueous phase was isolated and 0.6 volumes of $45 \mathrm{mM}$ acetic acid in ethanol were added. After an incubation period of $16 \mathrm{~h}$ at $-20^{\circ} \mathrm{C}$, RNA was precipitated by centrifugation at $10,000 \mathrm{~g}$ for $20 \mathrm{~min}$. RNA was dissolved in $50 \mu \mathrm{l}$ of $50 \mu \mathrm{g} / \mathrm{ml}$ proteinase $\mathrm{K}, 10 \mathrm{mM}$ Tris$\mathrm{HCl}, 5 \mathrm{mM}$ EDTA, $0.5 \%$ sodium dodecyl sulfate (SDS), pH 7.8 (preincubated for $15 \mathrm{~min}$ at $37^{\circ} \mathrm{C}$ ), and incubated for $1 \mathrm{~h}$ at $37^{\circ} \mathrm{C}$. Next, $50 \mu$ l water was added and the solution was extracted with $100 \mu \mathrm{l}$ phenol-chloroform-isoamylalcohol $(25: 24: 1, \mathrm{v} / \mathrm{v} / \mathrm{v}), \mathrm{pH}$ 8.0. The aqueous phase was isolated and 0.1 vol $3 \mathrm{M}$ sodium acetate, pH 5.2 and 3 vol ethanol were added. After $30 \mathrm{~min}$ at $-70{ }^{\circ} \mathrm{C}$ RNA was precipitated by centrifugation at $10,000 \mathrm{~g}$ for $20 \mathrm{~min}$. The yield was $1.7 \pm 0.1 \mu \mathrm{g}$ RNA per mg tissue ${ }^{2}$.

\section{Northern-and dot-blot analysis}

For Northern blot analysis RNA of the SON and PVN pooled from 4 animals was denatured with glyoxal and dimethylsulfoxide, fractionated on $1.4 \%$ agarose gels and transferred to a nylon membrane (Hybond-N, Amersham, U.K.) ${ }^{2}$. For dot-blot analysis one-fourth of the RNA isolated from SON, PVN and cortex tissue was dissolved in $50 \mu 16.7 \times \mathrm{SSC}(1$ $\times \mathrm{SSC}=150 \mathrm{mM}$ sodium chloride $-15 \mathrm{mM}$ sodium citrate, $\mathrm{pH} 7.0$ ), $7.4 \%$ formaldehyde at $65^{\circ} \mathrm{C}$ for 15 min. The samples, which were in duplicates, were cooled to $0{ }^{\circ} \mathrm{C}$ and spotted with a dot-blot apparatus (Bio-Dot microfiltration apparatus, Bio-Rad, CA, U.S.A.) on Hybond-N membrane. The blots are shortly washed in $2 \times \mathrm{SSC}$, dried, and baked at $85^{\circ} \mathrm{C}$ for $2 \mathrm{~h}$.

The blots were hybridized with the ${ }^{32} \mathrm{P}$-labeled single-stranded $\mathrm{O}^{\prime} \mathrm{I}$ - and $\mathrm{VP}$-specific probes, MPB-5 and MPB-1 respectively ${ }^{2}$, at $55{ }^{\circ} \mathrm{C}$ in the presence of $10 \%$ dextran sulfate. After hybridization, the blots were washed twice in $2 \times \mathrm{SSC}-0.1 \%$ SDS for $5 \mathrm{~min}$ at room temperature, once in $0.5 \times \mathrm{SSC} 0.1 \% \mathrm{SDS}$ at $50-60{ }^{\circ} \mathrm{C}$ for $15 \mathrm{~min}$, and once in $0.1 \times \mathrm{SSC}-0.1 \%$ SDS at $65^{\circ} \mathrm{C}$ for $15 \mathrm{~min}$. The blots were exposed to X-ray film (Kodak XAR-5 (Eastman Kodak, Rochester, NY)) with an intensifying screen at $-70{ }^{\circ} \mathrm{C}$ for various lengths of time. For rehybridization the probe was removed from the blots by washing at $60{ }^{\circ} \mathrm{C}$ in $50 \%$ formamide, $10 \mathrm{mM}$ Tris-HCl-10 mM EDTA, pH 8.0 for $1 \mathrm{~h}$. Completeness of probe re- 
moval was checked by autoradiography of the blots.

\section{Image analysis}

The autoradiographic signals from the Northern and dot-blots were quantitated by determination of the optical density (OD) using a VIPER image analysis system (Gesotec, Darmstadt, F.R.G.) equipped with a Hitachi CCD-videocamera (Hitachi, Tokyo, Japan). The area with the specific hybridization signal is automatically contoured using a preset OD limit which is kept constant throughout the measurements. The average OD of these contoured areas is determined. The OD of the background next to the measured areas is subtracted from the OD value obtained from these areas.

Measurement of the $\mathrm{OD}$ of the signals from the Northern blots provided a relative index for the changes in mRNA levels. The percentual changes in mRNA levels are based on the average ODs of the total specific RNA bands on the autoradiograms. These ODs were converted to arbitrary units of mRNA using a film response curve which was obtained from dot-blots with known amounts of MPB-4 and MPB-2 which are the DNA complements of the ${ }^{32} \mathrm{P}$-labeled probes MPB-5 and MPB-1 respectively ${ }^{1}$. These dot-blots were hybridized and exposed together with the Northern blots.

Quantitative measurements of the VP mRNA and OT mRNA contents of the samples were done by dot-blots using known amounts of MPB-2 and MPB-4 DNA as standards which were spotted on the same blot. The RNA samples on the dot-blots were diluted such that their ODs were in the linear part of the standard curve. The OD values are converted by the standard curves and corrected for the dilution factor of the sample. The cortex values were subtracted from the values obtained for the different nuclei resulting in values which represents the total amount of OT or VP mRNA per SON.

\section{Radioimmunoassay}

OT and VP were extracted from the pituitary gland ${ }^{5}$ and measured by radioimmunoassay (RIA) according to Dogterom ${ }^{9,10}$, using the VP-antiserum $\mathrm{W} 1 \mathrm{E}$ and the OT-antiserum $02^{17}$. Each pituitary extract was measured in two dilutions. The final dilutions for the VP-antiserum was 1:240,000 and for the OT antiserum was 1:16,000. The amount of iodi- nated tracer in the RIA was $4000 \mathrm{cpm}$. Sensitivity of the VP-RIA was $0.5 \mathrm{pg} \mathrm{VP/tube}(90 \%$ tracer displacement). Fifty percent displacement was obtained with $8 \mathrm{pg} \mathrm{VP/tube.} \mathrm{Intra-} \mathrm{and} \mathrm{interassay} \mathrm{coefficients}$ of variation are $10 \%$ and $20 \%$, respectively. The OTRIA had a sensitivity of $4 \mathrm{pg}$ OT/tube $(90 \%$ tracer displacement) and $50 \%$ displacement was obtained at $40 \mathrm{pg} \mathrm{OT} /$ tube. Intra- and interassay coefficients of variation of the OT-RIA are $10 \%$ and $20 \%$, respectively.

\section{RESULTS}

\section{Blood pressure}

In 4-week-old SHR blood pressure was significantly higher than in 4-week-old WKY. The mean arterial pressure ( \pm S.E.M.) of WKY of 4 weeks of age was $101 \pm 5 \mathrm{~mm} \mathrm{Hg}(n=6)$ and of SHR $117 \pm 4 \mathrm{~mm}$ $\mathrm{Hg}(n=6)(P<0.05$; Student's $t$-test $)$. This difference in blood pressure was more pronounced at 10 weeks when the WKY had a mean arterial pressure ( \pm S.E.M.) of $124 \pm 6 \mathrm{~mm} \mathrm{Hg}(n=8)$ and that of the SHR was $168 \pm 3 \mathrm{~mm} \mathrm{Hg}(n=9 ; P<0.05$, Student's $t$-test).

\section{$V P M R N A$ and $O T M R N A$ in the SON and PVN}

Northern blot analysis of VP mRNA from the SON and PVN showed that the 4- and 10-week-old SHR had higher VP mRNA levels in both nuclei than age-matched WKY (Table I and Fig. 1). Dot-blot analysis, which is more precisely standardized, showed that at 4 weeks of age the SHR contained significantly (ANOVA) 1.8- and 2.7-fold more VP mRNA than the WKY in the SON and PVN respectively. At 10 weeks of age, VP mRNA levels were still higher in the SON and PVN of the SHR, but the difference between the two strains was reduced. The SON of the SHR contained significantly 1.3-fold more VP mRNA, and 1.4-fold higher levels (non-significant) were present in the PVN as compared to WKY. During the development from 4 to 10 weeks the VP mRNA levels in the SON and PVN of the WKY increased 1.4- and 2.4-fold. The VP mRNA levels in the SHR did not change during the developmental period studied according to dot-blot analysis (Fig. 2), but a developmental increase in VP mRNA was still observed by Northern blot analysis (Table I). 


\section{TABLE I}

Relative VP and OT $M R N A$ content of the supraoptic nucleus (SON) and paraventricular nucleus (PVN) of 4- and 10-weekold SHR determined by Northern blot analysis

The VP and OT mRNA contents are expressed as the mean percentage of the optical density value obtained from two Northern blots in which the VP and OT mRNA content in the SON of the 10-week-old WKY is set as $100 \%$

\begin{tabular}{|c|c|c|c|c|}
\hline \multirow{2}{*}{ Brain area } & \multirow[t]{2}{*}{ Age (weeks) } & \multicolumn{2}{|c|}{$V P \operatorname{mRNA}(\%)$} & \multirow[b]{2}{*}{$W K Y / S H R$} \\
\hline & & $W K Y$ & $S H R$ & \\
\hline SON & 4 & 80 & 100 & 0.8 \\
\hline SON & 10 & 100 & 155 & 0.6 \\
\hline PVN & 4 & 15 & 30 & 0.5 \\
\hline \multirow[t]{2}{*}{ PVN } & 10 & 50 & 75 & 0.7 \\
\hline & & \multicolumn{2}{|c|}{$O T m R N A(\%)$} & \\
\hline SON & 4 & 50 & 25 & 2.0 \\
\hline SON & 10 & 100 & 45 & 2.2 \\
\hline PVN & 4 & 55 & 35 & 1.6 \\
\hline PVN & 10 & 80 & 60 & 1.3 \\
\hline
\end{tabular}

Rehybridization of the dot-blots and Northern blots with an OT mRNA specific probe showed that OT mRNA levels of the SON were significantly (ANOVA) 35\% lower in the SHR of 4 weeks and 10

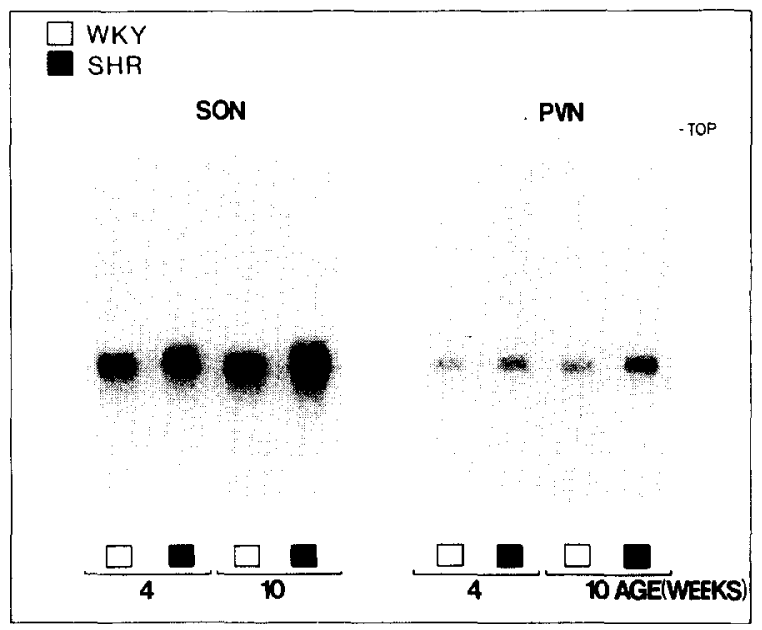

Fig. 1. VP mRNA detected on Northern blots of RNA isolated from the SON (left panel) and PVN (right panel) of 4- and 10week-old SHR and WKY. Each lane contained total RNA pooled from 4 rats. The approximate length of VP mRNA was 700 bases as determined by M13 HpaII restricted DNA size markers.

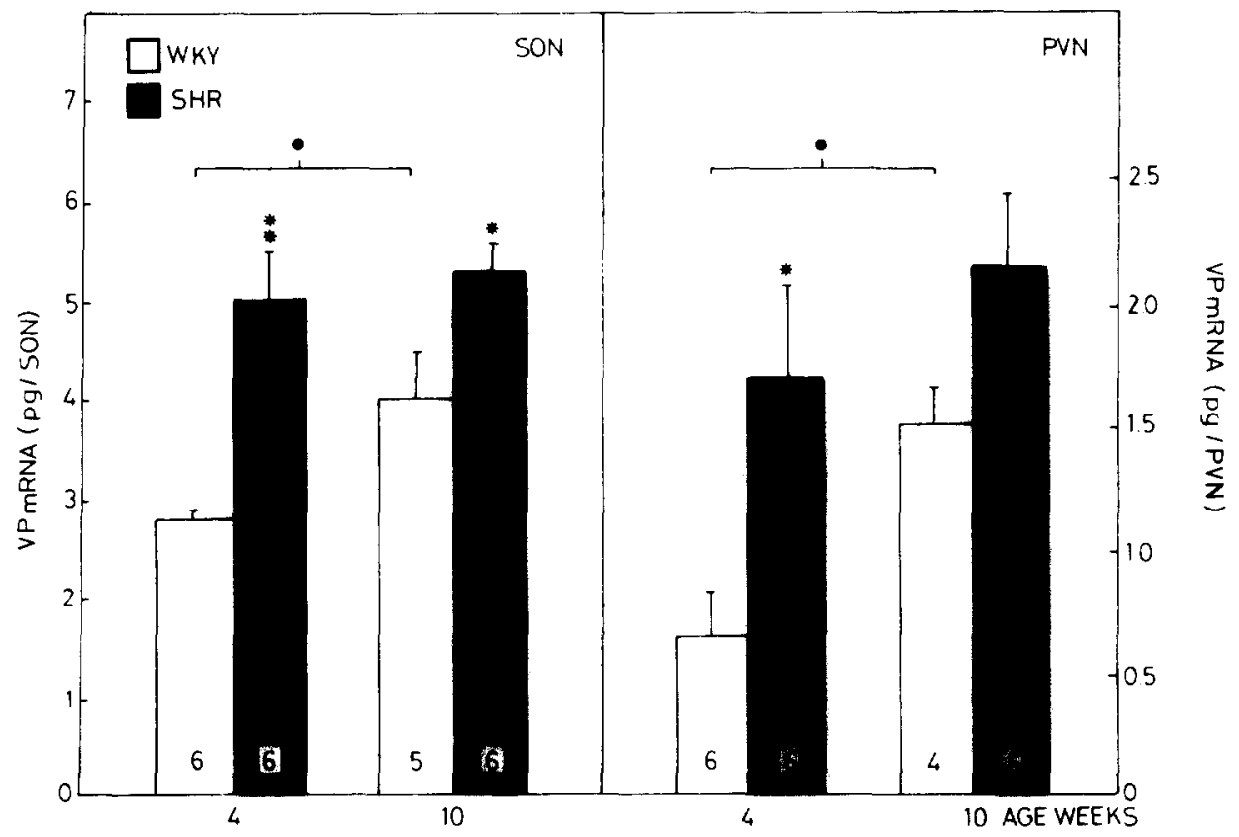

Fig. 2. VP mRNA content of the SON and PVN of 4- and 10-week-old SHR and WKY as determined by dot-blot analysis. VP mRNA levels are expressed in py as the nean $\perp$ S.E.M. The number of animals is indicated at the bottom of the column. Statistical significance was tested by ANOVA and Student's $t$-test. Age-matched SHR versus WKY, ${ }^{*} P<0.05,{ }^{* *} P<0.01 ; 4$ - versus 10 -week-old rats, $\bullet<0.05$ (Student's $t$-test). 


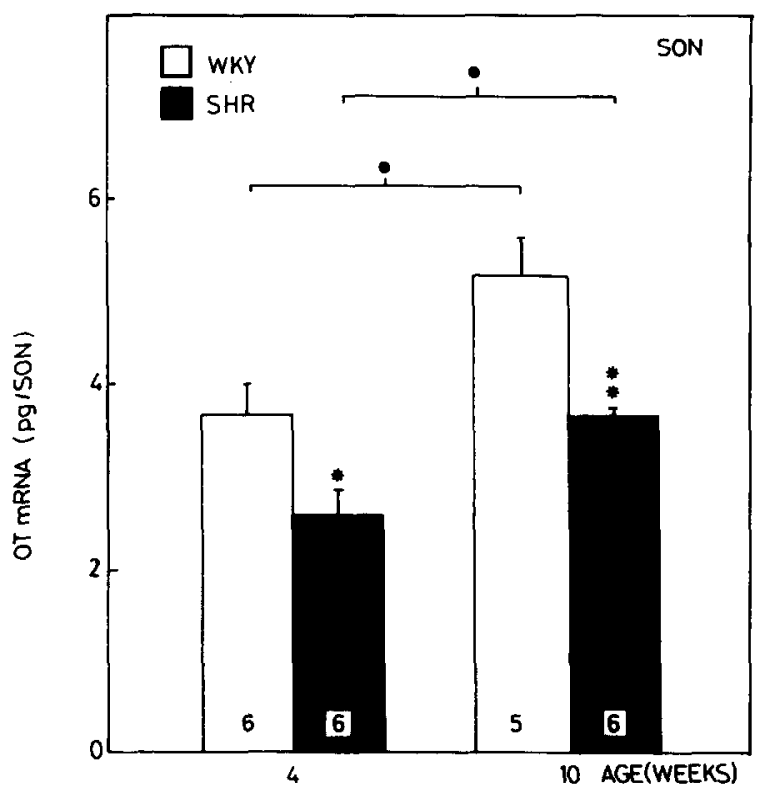

Fig. 3. OT mRNA content of the SON of 4- and 10-week-old SHR and WKY rats as determined by dot-blot analysis. Values are expressed in pg of OT mRNA as the mean \pm S.E.M. and the number of animals is indicated at the bottom of the column. Statistical significance was tested by ANOVA and Student's $t$ test. Age-matched SHR versus WKY, ${ }^{*} P<0.05,{ }^{*} P<0.01$; 4- versus 10 -week-old rats, ${ }^{\bullet} P<0.05$ (Student's $t$-test).

WKY (Table I and Fig. 4). Furthermore, both SHR and WKY showed a 1.4-fold increase in OT mRNA content of the SON during aging from 4 to 10 weeks (Fig. 3). This was in agreement with Northern blot analysis which indicated a 2- and 1.5-fold increase in the SON and PVN respectively of SHR and WKY (Table I and Fig. 4).

\section{$V P$ and $O T$ content of the pituitary gland and VP plas- ma level}

At 4 weeks of age, pituitary VP and OT contents were not different between SHR and WKY. However, at 10 weeks of age, the SHR had a 1.5 -fold higher pituitary VP content than the WKY, while the OT content was 1.3-fold lower in the SHR (Fig. 5). In both 4- and 10-week-old SHR the VP plasma levels were approximately 1.5 -fold higher (ANOVA) than in WKY (Fig. 6).

\section{DISCUSSION}

The higher levels of VP mRNA and lower levels of OT mRNA in the SON and PVN of the SHR com-

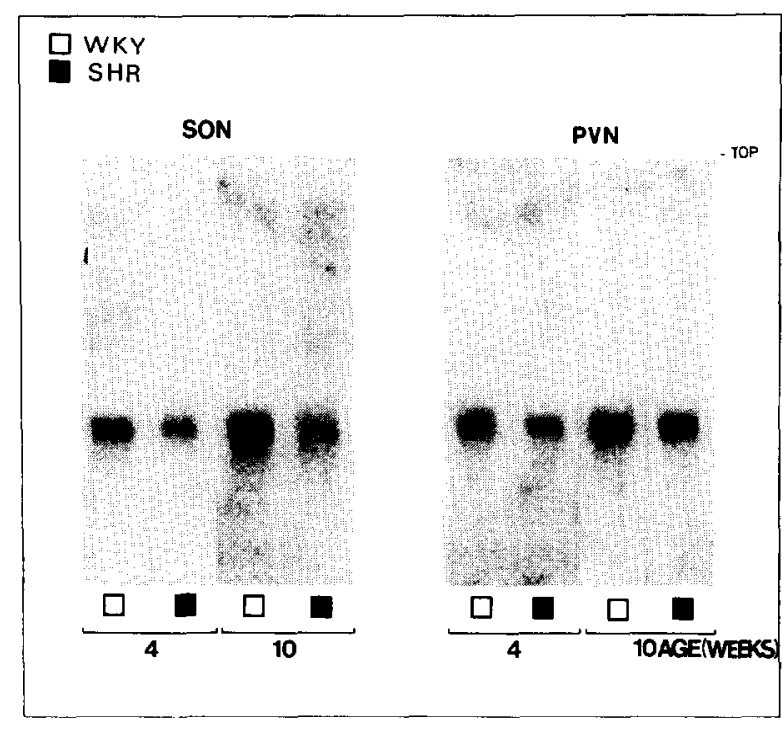

Fig. 4. OT mRNA detected on Northern blots of total RNA preparations from the SON (left panel) and PVN (right panel) of 4- and 10-week-old SHR and WKY. The lanes contained total RNA preparations pooled from 4 animals. The length of OT mRNA was approximately 650 bases as determined by DNA size markers (cf. Fig. 1).

pared to the WKY are indicative for a higher level of expression of the VP gene and a lower expression of the OT gene in te SHR. These changes in VP and OT mRNA levels cannot be caused by cell division and migration during development since these processes already stop before birth ${ }^{11,15,38,47,48}$. There are no differences between the SHR and the WKY with respect to the number of vasopressinergic neurons in the $\mathrm{SON}^{40}$ and the total number of magnocellular neurons in the $\mathrm{SON}^{28}$. It has been reported that the PVN of the SHR has a reduced amount of magnocellular neurons ${ }^{28}$. However, it has not been determined if this is in the vasopressinergic and/or oxytocinergic cell population and whether the number of parvocellular neurons is different. This means that differences in VP and OT mRNAs in the SON are not caused by differences in the number of vasopressinergic and oxytocinergic neurons. The reduced amount of magnocellular neurons in the PVN indicate that the higher VP mRNA levels in this nucleus are caused by a higher level of VP gene expression, but the lower OT mRNA levels in the PVN could be the result of a lesser amount of oxytocinergic neurons. Alternatively, differences in mRNA stability cannot yet be excluded. By using the punch technique of Palkovits ${ }^{32}$ 


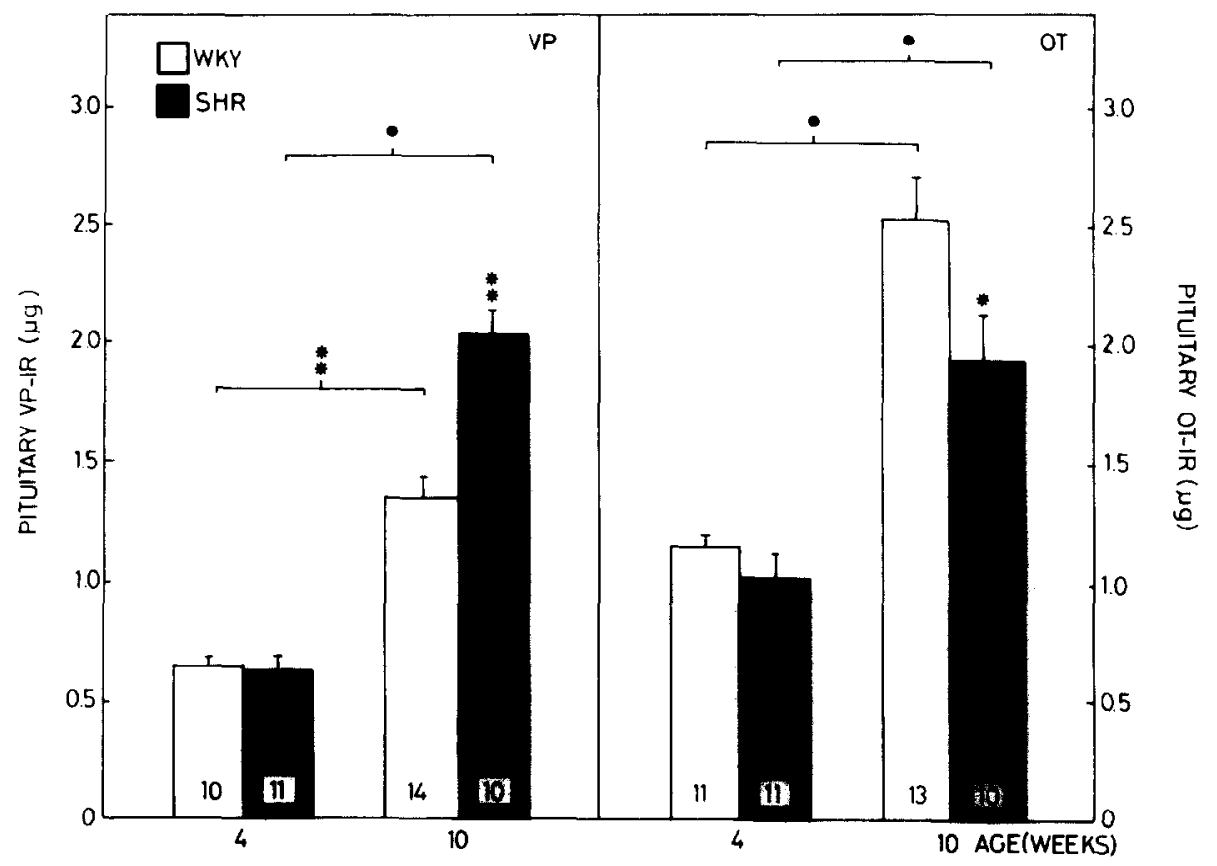

Fig. 5. The pituitary contents of VP (left panel) and OT (right panel) in 4- and 10-week-old SHR and WKY. The VP and OT immunoreactivity (IR) are expressed as the mean $(\mu \mathrm{g}) \pm \mathrm{S}$.E.M., and the number of rats is indicated at the bottom of the column. Statistical significance was tested by ANOVA and Student's $t$-test. Age-matched SHR versus WKY, ${ }^{*} P<0.05 ; 4$ - versus 10 -week-old rats, ${ }^{\bullet} P<$ 0.01 (Student's $t$-test).

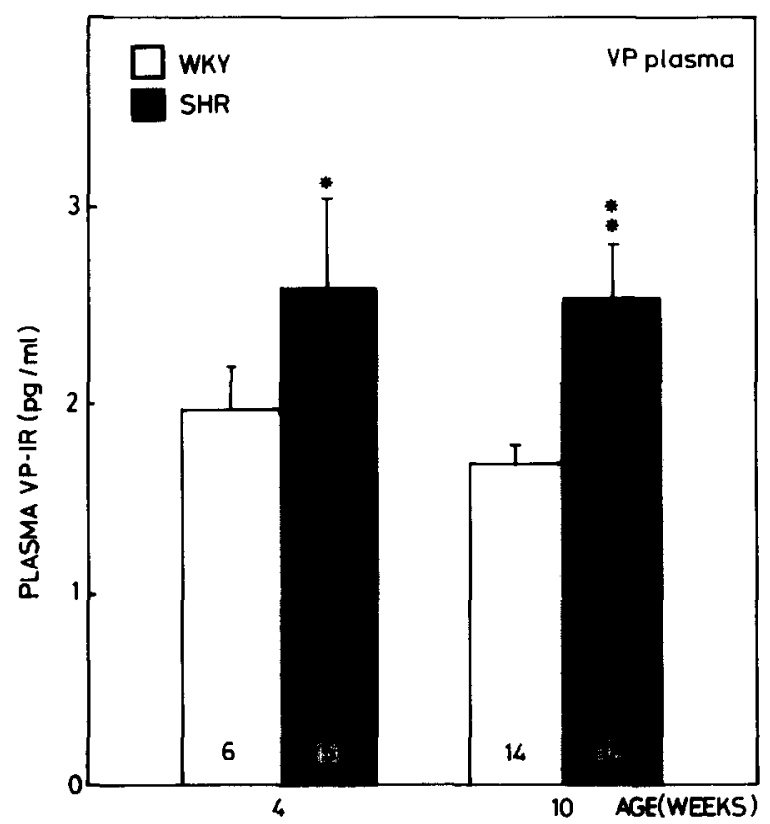

Fig. 6. Plasma levels of VP in 4 - and 10 week-old SHR and WKY as determined by radioimmunoassay. The levels are expressed in $\mathrm{pg} \mathrm{VP} / \mathrm{ml} \mathrm{VP}$ as the mean $\pm \mathrm{S}$.E.M. The number of animals is indicated at the bottom of the column. Statistical significance between WKY and SHR was tested by ANOVA. *P $<0.05,{ }^{* *} P<0.01$ we obtained the average level of the VP MRNA and OT mRNA content per total nucleus. However, a change or difference does not need to occur evenly in all the neurons of the SON and PVN, but could be limited to a certain population of neurons as has been found for example following osmotic stimulation by in situ hybridization ${ }^{19}$.

Several reports on VP levels in plasma and in the hypothalamo-neurohypophyseal system indicate that the SHR has a higher basal VP release as compared to $W K Y^{7} \cdot 16,21,22.25 .36,41$. On the other hand in other reports differences in VP plasma levels were not found ${ }^{31,34}$. This may be due to strain differences. A higher level of VP gene expression in the hypothalamo-neurohypophyseal system of 4-week-old SHR accompanied by unchanged VP pituitary levels and higher plasma levels indicate that VP biosynthesis and release are both higher in the 4-week-old SHR. In the 10-week-old SHR VP mRNA levels remain higher although the difference with the WKY is less prominent. This is accompanied by higher VP pituitary and plasma levels indicating that a higher rate of biosynthesis and release of VP is still present in the SHR later in development. In itself the elevation of 
plasma VP levels in the SHR is insufficient to increase blood pressure ${ }^{20}$.

The VP pituitary content is the net result of VP synthesis and release. The net result of synthesis and release of VP in young SHR and WKY is similar since VP pituitary contents are not different between both strains. However, the VP mRNA and VP plasma levels are higher in the SHR. In SHR of 10 weeks of age the VP pituitary content also is higher, suggesting that, compared to young SHR and WKY, there is a different balance in VP synthesis and release between 10-week-old SHR and WKY. Studies on VP release support the view that increased release is due to hyper-responsiveness of the VP system in young $\mathrm{SHR}^{37}$, which may stimulate VP gene expression. Later in the hypertensive phase this hyper-responsiveness disappears ${ }^{37}$ which suggests that the high VP gene expression has become constitutive.

The level of OT gene expression of the hypothalamo-neurohypophyseal system of the SHR changed in a direction opposite to that of VP gene expression. In 4- and 10-week-old SHR OT mRNA levels are lower than in the WKY. OT pituitary levels are the same at 4 weeks but lower in 10 -week-old SHR. These lower OT pituitary levels at 10 weeks are accompanied by lower OT plasma levels, as has been measured in 17 week-old animals ${ }^{36}$. This again indicates that young SHR and WKY have a similar balance in synthesis and release while the older SHR and WKY have a different balance and suggests that the lower expression of the OT gene has become constitutive in the old SHR, resulting in decreased OT pituitary and plasma levels.

The VP systems primarily to brainstem areas are of interest since baroreceptor responses and cardiovascular functions are mediated via brainstem areas, primarily via the nucleus tractus solitarii ${ }^{13,21,50}$. Both vasopressinergic and oxytocinergic neurons from the PVN project to brainstem areas ${ }^{29,46,51}$. Furthermore, VP administration via the cisterna magna, spinal cord or into the nucleus tractus solitarii increases blood pressure in rats ${ }^{14,18,43}$. On the other hand it has been reported that low doses of i.c.v. given vasopressin decreases the sensitivity of the baroreceptor heart reflex ${ }^{1}$. Moreover, intracisternal injected VP can result in a reduction of pressor responses induced by stimulation of the afferent nervus vagus in $\operatorname{dog}^{24}$, and that intracerebroventricular administration of
VP and OT in rats inhibited a pressor response induced by electrical stimulation of the mesencephalic reticular formation ${ }^{44,45}$. These data indicate that endogenous VP and OT of the brainstem may participate in blood pressure regulation. Mohring et al. ${ }^{23}$ found that there was no difference in brainstem VP and OT levels in 3-week-old stroke-prone SHR (SHRSP), but that at 7 weeks and later VP and OT levels were lower. Although the subset of neurons from the PVN that project to the lower brainstem could have a different level of gene expression than indicated by the overall mRNA levels of the PVN which were measured here, the higher VP mRNA levels in the PVN and lower VP content in the brainstem of old SHRSP suggest that VP release is enhanced in the brainstem of old SHR(SP). Furthermore, the higher VP mRNA levels in the PVN of the young SHR and the similar levels of VP in the brainstem of young SHRSP suggest that VP release is already enhanced in young SHR(SP). The lower OT levels in older rats could then be a result of increased release and/or decreased biosynthesis. If the overall mRNA levels of the PVN reflect the mRNA levels of those neurons projecting to the brainstem than the VP mRNA and OT mRNA content of the PVN suggests that the biosynthetic capacity of the vasopressinergic neurons is higher and of oxytocinergic neurons is lower in this extra-hypothalamic system compared to controls.

Arguments against a role of VP in hypertension of SHR were put forward by Lang et al. ${ }^{16}$ who made a cross-breeding of VP-deficient Brattleboro rats (DI) with SHRSP. These SHRSP-DI rats, which are VPdeficient, still develop hypertension. However, in view of the blood pressure increasing effect of OT after application to the nucleus tractus solitarii ${ }^{18}$ it should be noted that the OT system of the Brattleboro rat is markedly activated, as indicated by high OT mRNA levels in SON and PVN ${ }^{3,49}$ and high OT plasma levels ${ }^{10}$. The decreased OT levels in the pituitary gland and the hypothalamus of the SHRSP-DI ${ }^{16}$ could reflect a similar activation of the OT system in this hybrid strain and may have consequences for the development of hypertension.

From the present observations it is concluded that VP gene expression and release are enhanced in the hypothalamo-neurohypophyseal system of the SHR during the development of hypertension, while OT 
gene expression is reduced. The data suggest that these strain differences may be primarily caused by differences in release of the neurohypophyseal hormones. Later in development differences in VP and OT gene expression between SHR and WKY may be the main cause for the observed alterations. The observations in this study are not conclusive whether VP and/or OT relate to the cause of hypertension development. They rather indicate that the enhanced activity of the VP system and reduced activity of the OT system are not a consequence of the development of hypertension. OT, may play a role in the development of hypertension in the SHR.

\section{REFERENCES}

1 Bratström, A., De Jong, W. and De Wied, D., Barorezeptoriches Herz-Reflex während zentraler Vasopressinwirkung, Z. Klin. Med., 41 (1986) 1257-1259.

2 Burbach, J.P.H., Van Tol, H.H.M., Bakkus, M.H.C., Schmale, H. and Richter, D., Quantification of vasopressin mRNA and oxytocin mRNA in hypothalamic nuclei by solution hybridization assays, J. Neurochem., 47 (1986) 1814-1821

3 Burbach, J.P.H., Van Tol, H.H.M., Snijdewint, F.G.M., Boer, G.J., Voorhuis, Th.A.M., Liu, B. and De Wied, D., Regulation of the mutant vasopressin gene and the oxytocin gene of the homozygous Brattleboro rat: ontogeny of mRNAs and effect of DDAVP treatment, Soc. Neurosci. Abstr., (1986) 188.9.

4 Burbach, J.P.H., Voorhuis, Th.A.M., Van Tol, H.H.M. and Ivell, R., In situ hybridization of oxytocin messenger RNA: macroscopic distribution and quantitation in rat hypothalamic nuclei, Biochem. Biophys. Res. Commun., 145 (1987) 10-14.

5 Burbach, J.P.H., Wang, X.-C., Ten Haaf, J.A. and De Wied, D., Substances resembling C-terminal vasopressin fragments are present in the brain but not in the pituitary gland, Brain Res., 306 (1984) 284-287.

6 Crofton, J.T., Rockhold, R.W., Share, L., Wang, B.C., Horovitz, Z.P., Manning, M. and Sawyer, W.H., Effects of intracerebroventricular captopril on vasopressin and blood pressure in spontaneously hypertensive rats, Hypertension, 3 Suppl. II (1981) II71-II74

7 Crofton, J.T., Share, L., Shade, R.E., Allen, C. and Tarnowski, D., Vasopressin in the rat with spontaneous hypertension, Am. I. Physiol., 234 (1978) H361-H366.

8 DeVito, W.J., Miller, M. and Sutterer, J.R., Increased secretion of vasopressin and adenosine $3^{\prime}, 5^{\prime}$-monophosphate from hypothalamo-posterior pituitary units of spontaneously hypertensive rats, Endocrinology, 111 (1982) 1958-1963.

9 Dogterom, J., Van Wimersma Greidanus, Tj.B. and De Wied, D., Vasopressin in cerebrospinal fluid and plasma of man, dog, and rat, Am. J. Physiol., 234 (1978) E463-E467.

10 Dogterom, J., Van Wimersma Grcidanus, Tj.B. and Swaab, D.F., Evidence for the release of vasopressin and oxytocin into cerebrospinal fluid: measurements of intact

\section{ACKNOWLEDGEMENTS}

The authors thank Drs. H. Schmale, R. Ivell and D. Richter (Hamburg, F.R.G.) for the gift of the subclone pVP $\lambda$ PstI and pO $\lambda B$ all of the rat VP and OT genes. We thank Mrs. I. van de Heerik and Mr. L. van Halewijn for their assistance, and Dr. M. Seger for correcting the manuscript. M. v.d. B. is supported by the Dutch Heart Foundation (Grant 84.061). H.Il.M.v.T. is supported by the Foundation of Medical and Health Research MEDIGON (Grant 900-546-044).

and hypophysectomized rats, Neuroendocrinology, 24 (1977) 108-118.

11 Fischer, A.W.F., Gill, V., Wong, K., Raghatvan, S., North, W. and Lederis, K., Anatomical and developmental aspects of neurons terminating in the posterior pituitary. In D.S. Farner and K. Lederis (Eds.), Neurosecretion, Molecules, Cells, Systems, Plenum, New York, 1981, 39-47

12 Gainer, H., Precursors of vasopressin and oxytocin, Prog Brain Res., 60 (1983) 205-215.

13 Gardiner, S.M. and Bennett, T., Endogenous vasopressin and baroreflex mechanisms, Brain Res. Rev., 11 (1986) 317-338.

14 Gunther, O., Kovacs, G.L., Szabo, G. and Teledgy, G., Opposite effects of intraventricular and intracisternal administration of vasopressin on blood pressure in rats, Peptides, 7 (1986) 539-540.

15 Kachaturian, H. and Sladek Jr., J.R., Simultaneous monoamine histofluorescence and neuropeptide immunocytochemistry III. Ontogeny of catecholamine varicosities and neurophysin neurons in the rat supraoptic and paraventricular nuclei, Peptides, 1 (1980) 77-95.

16 Lang, R.E., Ganten, D., Ganten, U., Rascher, W. and Unger, Th., Pathogenesis of hypertension in spontaneously hypertensive rats: definite evidence against a role of vasopressin, Clin. Exp. Hyp., A6 (1984) 121-138.

17 Liu, B. and Burbach, J.P.H., Characterization of vasopressin and oxytocin immunoreactivity in the sheep and rat pineal gland: absence of vasotocin and detection of a vasopressin-like peptide, Peptides, 8 (1987) 7-11.

18 Matsuguchi, H., Sharabi, F.M., Gordon, F.J., Johnson, A.K. and Schmid, P.G., Blood pressure and heart rate response to microinjection of vasopressin into the nucleus tractus solitarius region in the rat, Neuropharmarology, 21 (1982) 687-693.

19 McCabe, J.T., Morrell, J.I., Richter, D. and Pfaff, D.W., Localization of neuroendocrinologically relevant RNA in brain by in situ hybridization. In W.F. Ganong and L. Martini (Eds.), Frontiers in Neuroendocrinology, Raven, New York, 1986, pp. 149-167.

20 McNeill, J.R., Role of vasopressin in the control of arterial pressure, Can. J. Physiol. Pharmacol., 61 (1983) 1226-1235.

21 Miura, M. and Reis, D.J., Termination of secondary projections of carotid sinus nerve in the cat brain stem, Am. J. 
Physiol:, 217 (1969) 142-153.

22 Mohring, J., Kintz, J, and Schoun, K., Studies on the role of vasopressin in blood pressure control of spontaneously hypertensive rats with established hypertension (SHR, Stroke-Prone strain), J. Cardiovasc. Pharmacol., 1 (1979) 593-608.

23 Mohring, J., Schoun, J., Kintz, J., Robinson, I.C.A.F. and McNeill, J.R., Vasopressin and oxytocin content are decreased in the brain stems of spontaneously hypertensive rats, Neuroendocrinology, 36 (1983) 457-461.

24 Montastruc, P., Dang Tran, L. and Montastruc, J.L., Reduction of vagal pressor reflexes by neurohypophyseal peptides and related compounds, Eur. J. Pharmacol., 117 (1985) 355-361.

25 Morris, M., Neurohypophyseal response to dehydration in the spontaneously hypertensive rat, Hypertension, 4 (1982) 161-168.

26 Morris, M., Ross, J. and Sundberg, D.K., Catecholamine biosynthesis and vasopressin and oxytocin secretion in the spontaneously hypertensive rat: an in vitro study of localized brain regions, Peptides, 6 (1985) 949-955.

27 Negro-Vilar, A. and Saavedra, J.M., Changes in brain stem somatostatin and vasopressin levels after stress in spontaneously hypertensive and Wistar-Kyoto rats, Brain Res. Bull., 5 (1980) 353-358.

28 Nelson, D.O. and Boulant, J.A., Altered CNS neuroanatomical organization of spontaneously hypertensive (SHR) rats, Brain Res., 226 (1981) 119-130.

29 Nilaver, G., Zimmerman, E.A., Wilkins, J., Michaels, J, Hoffman, D. and Silverman, A.J., Magnocellular hypothalamic projections to the lower brain stem and spinal cord of the rat: immunocytochemical evidence for predominance of the oxytocin-neurophysin system compared to the vasopressin-neurophysin system Neuroendocrinology, 30 (1980) 150-158.

30 Okamoto, K. and Aoki, K., Development of a strain of spontaneously hypertensive rats, Jpn. Circ. J., 27 (1963) 282-293.

31 Ota, K., Share, L., Crofton, J.T. and Brooks, D.P., Metionine-enkephalin and vasopressin in SHR: effects of dehydration, Am. J. Physiol., 250 (1986) R1007-R1013.

32 Palkovits, M., Isolated removal of hypothalamic or other brain nuclei of the rat, Brain Res., 59 (1973) 449-450.

33 Pickering, B.T., The neurosecretory neuron: a model system for the study of secretion, Essays Biochem., 14 (1978) 45-81.

34 Rascher, W., Weidman, E. and Gross, F., Vasopressin in the plasma of stroke-prone spontaneously hypertensive rats, Clin. Res. Lond., 61 (1981) 295-298.

35 Rockhold, R.W., Crofton, J.T., Brooks, D.P. and Share, L., The response of vasopressin and blood pressure to hemorrhage in SHR and WKY rats, Clin. Exp. Hyp., A6 (1984) $827-849$

36 Rosella-Dampman, L.M., Emmert, S.E., Keil, L.C. and Summy-Long, J.Y., Differential effects of naloxone on the release of neurohypophyseal hormones in normotensive and spontaneously hypertensive rats, Brain Res., 325 (1985) 205-214.

37 Sladek, C.D. and Blair, M.L., Cholinergic stimulation of vasopressin rclease in spontancously hypertensive rats, $\mathrm{Hy}$ pertension, 6 (1984) 855-860.

38 Sladek, C.D., Gash, D.M., Kachaturian, H., Scott, D.E. and Sladek Jr., J.R., Maturation of the supraoptic nucleus: a multidisciplinary analysis, Peptides, 1 Suppl. I (1980) $51-67$.

39 Sladek, C.D., Blair, M.L., Chen, Y.-H. and Rockhold, R.W., Vasopressin and renin response to plasma volume and loss in spontaneously hypertensive rats, Am. J. Physiol., 250 (1986) $\mathrm{H} 443-\mathrm{H} 452$.

40 Sladek Jr., J.R., Davis, B.J. and Sladek, C.D., Localization of vasopressin-neurophysin and norepinephrine in the supraoptic nucleus of spontaneously hypertensive rats, Brain Res., 365 (1986) 293-304.

41 Share, L., Vasopressin and cardiovascular regulation, Fed. Proc., 43 (1984) 78-79.

42 Share, L. and Crofton, J.T., Contributions of vasopressin to hypertension, Hypertension, 4 Suppl. III (1982) 85-92.

43 Tan, D.-P. and Tsou, K., New evidence for neuronal function of vasopressin: sympathetic mediation of intrathecal vasopressin-induced hypertension, Peptides, 7 (1986) $569-572$.

44 Versteeg, C.A.M., Bohus, B. and De Jong, W., Inhibition of centrally-evoked pressor respunses by neurohypophyseal peptides and their fragments, Neuropharmacology, 21 (1982) 1359-1364.

45 Versteeg, C.A.M., De Jong, W. and Bohus, B., Arginine ${ }^{8}$ vasopressin inhibits centrally induced pressor responses by involving hippocampal mechanisms, Brain Res., 292 (1983) 317-326.

46 White, J.D., Krause, J.E. and McKelvy, J.F., In vivo biosynthesis and transport of oxytocin, vasopressin and neurophysins to posterior pituitary and nucleus of the solitary tract, J. Neurosci., 4 (1984) 1262-1270.

47 Whitnall, M.H., Key, S., Ben-Barak, Y., Ozato, K. and Gainer, H., Neurophysin in the hypothalamo-neurohypophyseal system. II. Immunocytochemical studies of the ontogeny of oxytocinergic and vasopressinergic neurons, $I$. Neurosci., 5 (1985) 98-109.

48 Wolf, C. and Trautmann, B., Ontogeny of the hypothalamo-neurohypophyseal system in rats. An immunological study, Endokrinologie, 69 (1977) 222-226.

49 Young, W.S. III, Mezey, E. and Siegel, R.E., Vasopressin and oxytocin mRNAs in adrenalectomized and Brattleboro rats: analysis by quantitative in situ hybridization histochemistry, Mol. Brain. Res., 1 (1986) 231-241.

50 Zerbe, R.L. and Feuerstein, G., Cardiovascular regulation of centrally administered vasopressin in conscious and anesthesized rats, Neuropeptides, 6 (1985) 471-484.

51 Zimmerman, E.A., Nilaver, G., Hou-Yu, A. and Silverman, A.J., Vaspressinergic and oxytocinergic pathways in the central nervous system, Fed. Proc., 43 (1984) 91-96. 